Gut, 1980, 21, 480-485

\title{
Evaluation of colonic myoelectrical activity in health and functional disorders
}

\author{
L BUENO,* J FIORAMONTI, Y RUCKEBUSCH, J FREXINOS, AND P COULOM
}

From the Department of Physiology, Veterinary School and Gastroenterology Unit, CHU Rangueil, Toulouse, France

SUMMARY Electrical activity of the colon was investigated in six healthy volunteers and 22 patients presenting functional colonic disorders associated with pain, constipation, or diarrhoea. Myoelectrical activity during 10 hours, including two daily meals, was recorded from eight groups of nickel-chrome electrodes using a $1.5 \mathrm{~m}$ length probe introduced by the rectal route. Electromyograms of volunteers consisted of slow waves at two distinct rhythms, approximately 3 and 10 cycles per minute, during 16 to $28 \%$ of the recording time respectively for each site. Action potentials were also recorded as 11 to 80 short spike bursts (SSB) per hour lasting 1.5 to $3.5 \mathrm{~s}$ at any site and 20-26 long spike bursts (LSB) per hour, lasting 17 to $21 \mathrm{~s}$, occurring in series of four to eight propagated bursts. Additional high-velocity propagated bursts were recorded during the three hour postprandial period. Three typical changes in spike activity patterns were detected: an increase by $170-420 \%$ of the number of SSB associated to a high spiking activity was recorded in 13 patients (group I), the absence of SSB, a low spiking activity level and only 3 to 8 LSB per hour (group II), in six patients; and the postprandial response was absent (group III) in three other investigated patients. Evidence for three groups of motor disturbances and their possible relation to clinical manifestations of functional disorders is presented.

Despite considerable progress in the knowledge of human colonic motor function, the relationships between electrical and mechanical activity, their significance in regard to transit of digesta, and their temporal daily distribution in health and disease remain uncertain. ${ }^{1}$ Previous attempts to evaluate electrical activity of the colon in man have allowed the identification of two distinct slow-wave rhythms with frequencies of 9-12 and $2 \cdot 5-3.5 \mathrm{c} / \mathrm{min}$ respectively ${ }^{2-4}$ and, in one report, spike potentials were found to be superimposed on the higher slow-wave rhythm. ${ }^{2}$ Whereas the low frequency slow wave has the same incidence and frequency along the whole colon, the higher frequency slow wave has a greater incidence in the right colon, although its frequency is higher in the left colon. ${ }^{5}$ Lack of further information has been due to the technical difficulty of attaching clip or suction electrodes to the proximal colon. Failure to achieve adequate records of spiking activity was also due to the use of long time constants

*Address for reprint requests: Dr L Bueno, Department of Physiology, Veterinary School, 23 chemin des Capelles, 31076 Toulouse Cédex, France.

Received for publication 13 November 1979 to improve the recording of slow waves. ${ }^{4}$ In this study, the new approach to record spiking activity in the human colon was a flexible probe carrying electrodes (nickel-chrome) of small diameter $(0 \cdot 12$ $\mathrm{mm}$ ) introduced via the rectal route without any previous bowel clearance, a system already used successfully in the dog. In the latter species, the electromyogram gave a good correlation with that recorded from the corresponding serosal area. ${ }^{6}$

\section{Methods}

\section{PATIENTS}

Colonic myoelectrical activity was recorded in six healthy volunteers and 22 patients with functional colonic disorders during a 10 hour session from 9 to 19 hours, including two daily meals.

The two women and the four men (27-46 years of age) serving as controls had no history of gastrointestinal disease or previous abdominal surgery; all patients had a normal sigmoidoscopic examination and normal barium studies of the upper and lower gastrointestinal tract, all of them being symptomatic at the time of the study. They presented 
with either chronic diarrhoea, or constipation, or a combination of both symptoms lasting longer than two months with abdominal diffuse or localised pain related or not to meals (Table 1). Informed consent was obtained from each patient and control subject.

The EMG probe consisted of a radiologically opaque polyvinyl tube, $150 \mathrm{~cm}$ in length and $1 \mathrm{~cm}$ in diameter supporting eight groups of three electrodes at $10 \mathrm{~cm}$ intervals from the tip (Fig. 1A). The probe was introduced by the rectal route under sigmoidoscopy without air insufflation through a proctoscope 30 to 40 minutes before the recording session began. Introduction was stopped at the first sign of abdominal pain and the progression was radiographically controlled (Fig. 1B); no enema was given during the 24 hours preceding the recording session. Each electrode $(0.12 \mathrm{~mm}$ in diameter) consisted of a ring of nichrome wire ( $\mathrm{Ni} 80$ : $\mathrm{Cr}$ 20). The wires were insulated except for the discrete terminal loop anchored around the probe. This loop served as the sensor for the smooth muscle potentials via its mucosal contact. The groupings of three electrodes with $5 \mathrm{~mm}$ spacing ensured that there would be a pair suitable for bipolar recording should one of the wires break or not be in contact with the mucosa.

The free ends of the wires were connected to an eight-channel EEG machine (Minihuit Alvar, Paris), the electrical signals being amplified with a time constant of $0 \cdot 1 \mathrm{~s}$ without additional filters and recorded at a paper speed of $7.2 \mathrm{~cm} / \mathrm{min}$ and concomitantly picked up on a magnetic tape recorder with DC amplification. On three healthy subjects analysis of slow-wave frequency and presence has been made for the eight groups of electrodes by a two hour recording at a time constant of $1.2 \mathrm{~s}$ in place of $0 \cdot 1 \mathrm{~s}$.

Parietal pressure was simultaneously recorded during two recording periods in healthy vulunteers from one probe equipped with two strain gauges distant from $20 \mathrm{~cm}$ and placed $1 \mathrm{~cm}$ aborally to the corresponding electrode sites, the hardness of the tube being reduced at this place by reduction in its thickness.

Behavioural information (meals, micturition or defaecation, and activities or sensations) was reported directly on the EMG records. Records were stopped and the probe was withdrawn for patients presenting any sign of discomfort or pain that did not correspond with their previous pathological state (only one case).

Analysis of slow waves (frequency and duration) and of action potentials was made manually by visual inspection of both the direct and relayed EMG records for each channel.

A long spike burst was considered to be migratory when it was recorded with about the same time intervals between three consecutive electrode sites.

Table 1 Clinical details

\begin{tabular}{|c|c|c|c|c|c|c|c|c|}
\hline \multirow[b]{2}{*}{ Patient } & \multirow{2}{*}{\multicolumn{2}{|c|}{ Sex, age (yr) }} & \multirow[b]{2}{*}{$\begin{array}{l}\text { Length of } \\
\text { history }(y r)\end{array}$} & \multirow[b]{2}{*}{ 'Diarrhoea' } & \multirow[b]{2}{*}{ 'Constipation' } & \multirow[b]{2}{*}{$\begin{array}{l}\text { Stools frequency } \\
(1 \text { week })\end{array}$} & \multicolumn{2}{|c|}{ Abdominal pain } \\
\hline & & & & & & & $\begin{array}{l}\text { Related to } \\
\text { meals }\end{array}$ & Not related \\
\hline \multicolumn{9}{|c|}{ Constipation } \\
\hline 1 & $\mathbf{M}$ & 58 & 5 & 0 & ++ & 3 & 0 & 0 \\
\hline 2 & $\mathrm{~F}$ & 53 & 3 & 0 & ++ & 1 every $3 d$ & 0 & 0 \\
\hline 3 & $\mathbf{F}$ & 34 & 2 & 0 & $+t+$ & 1 every $3-4 d$ & 0 & $0 /+$ \\
\hline 5 & $\mathbf{M}$ & 42 & 2 & 0 & $+t+$ & $1-2$ & 0 & $0 /+$ \\
\hline 6 & $\mathbf{M}$ & 35 & 3 & $0 /+$ & $+t+$ & $2-12$ & + & +-+ \\
\hline 7 & $\mathrm{~F}$ & 61 & 4 & 0 & + & $<$ every 3 rd d & + & 0 \\
\hline 8 & $\mathbf{M}$ & 42 & 2 & 0 & $0 /+$ & $5-11$ & 0 & $+t+$ \\
\hline 9 & $\mathrm{~F}$ & 29 & 0.5 & $0 /+$ & $0 !+$ & 4 & 0 & $\because++$ \\
\hline 10 & $\mathrm{~F}$ & 31 & 1 & $0 /+$ & $0 /+$ & 5 & + & $+i$ \\
\hline 11 & $\mathbf{M}$ & 52 & $\mathrm{Nn}$ & 0 & +++ & $1-3$ & 0 & +-+ \\
\hline 12 & $\mathrm{~F}$ & 62 & 5 & 0 & $++t$ & $2-4$ & + & + \\
\hline 13 & $\mathbf{F}$ & 36 & 1 & 0 & ++ & $1-3$ & 0 & $+t$ \\
\hline \multicolumn{9}{|c|}{ Diarrhoea } \\
\hline 14 & $\mathbf{F}$ & 59 & 1 & $\div$ & 0 & $2-6 / d$ & 0 & +10 \\
\hline 15 & $\mathrm{~F}$ & 36 & 2 & -+ & 0 & $=3 / d$ & 0 & 0 \\
\hline 16 & $\mathbf{M}$ & 43 & 3 & +++ & 0 & $4-8 / d$ & 0 & 0 \\
\hline 17 & $\mathrm{~F}$ & 57 & 7 & ++ & 0 & $2-3 / d$ & 0 & ++ \\
\hline 18 & $\mathbf{M}$ & 57 & 4 & $+t+$ & $0 /+$ & up to $12 / \mathrm{d}$ & 0 & 0 \\
\hline 19 & $\mathrm{~F}$ & 40 & 3 & ++ & 0 & $>4 \mathrm{~d}$ & 0 & 0 \\
\hline \multicolumn{9}{|c|}{ Postprandial pain } \\
\hline 20 & $\mathrm{~F}$ & 63 & 1 & 0 & $0 /+$ & $6-7$ & +++ & 0 \\
\hline 21 & $\mathrm{~F}$ & 59 & 3 & 0 & $0 /+$ & $6-7$ & ++ & + \\
\hline 22 & $\mathrm{~F}$ & 36 & 0.5 & 0 & 0 & $5-6$ & $+t+$ & 0 \\
\hline
\end{tabular}

+-+++ indicates severity of symptoms. Nn: not noted. 

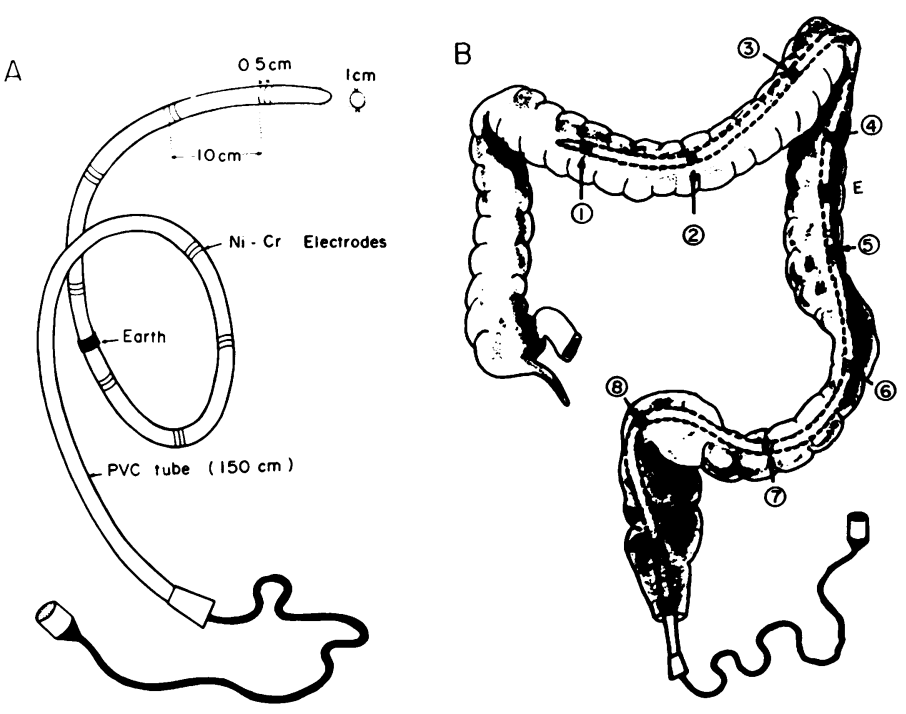

\section{Results}

\section{CHARACTERISTICS OF COLONIC}

MYOELECTRICAL ACTIVITY

In the six healthy subjects, electromyograms of the whole colon yielded the following patterns: two categories of slow wave having characteristic frequencies of 2-3 and 10-12 cycles/min independently of the site and appearing at one site during $16(7-13 \%)$ and $28 \%(13-46 \%)$ of the recording time respectively, obtained with a time constant of $1.2 \mathrm{~s}$; (2) action potentials (spikes) occurring in long spike bursts (LSB) lasting 19.6 $\pm 2.5 \mathrm{~s}$ (mean \pm SD) propagated either aborally or orally in 37 and $26 \%$ of the cases respectively on the $70 \mathrm{~cm}$ investigated length, and short spike bursts (SSB) appearing in isolation at a single site 11 to 80 times per hour with a duration of 1.5 to $3.5 \mathrm{~s}$ (Fig. 2). The LSB occurred at a frequency of $23 \cdot 2 \pm 4 \cdot 5$ per hour in series of 4 to 8 bursts (2-3 per min) having a similar iso- or antiperistaltic velocity of propagation of $4.2 \pm 1.5 \mathrm{~cm} / \mathrm{s}$, whereas SSB appeared located in series at a maximal frequency of 12 per min.

Simultaneous recording of EMG and parietal and intraluminal pressures showed that spiking activity was associated with colonic wall movements; Fig. 2 clearly shows that LSB are associated with pressure changes, although temporal association between each spike burst and pressure wave is not clearly demonstrated here (Fig. 2A). When only SSB were recorded, associated rhythmic pressure changes were detected on the mechanogram in more than $60 \%$ of cases (Fig. 2B). The amplitude of pressure changes associated with SSB was approximately 10 times lower than for the pressure peaks corresponding to LSB.

During the first three postprandial hours, this basic pattern was reinforced by the presence of
A

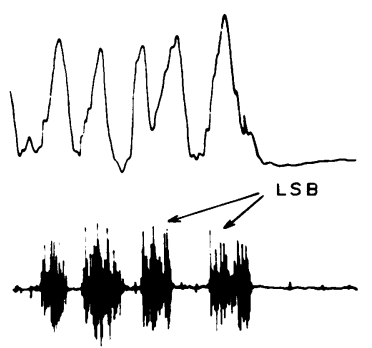

B

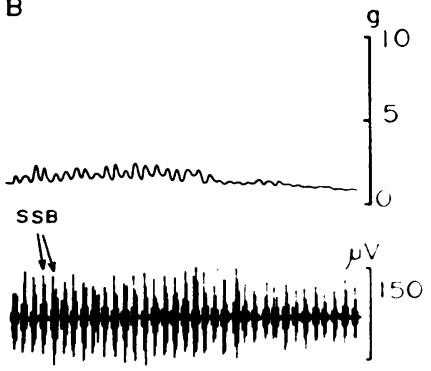

Fig. 2 Electrical activity (lower record) and mechanogram (upper record) obtained from a strain gauge placed $1 \mathrm{~cm}$ aborally to the electrodes on the same probe. LSB were associated with pressure changes (A) about 10 times higher than that observed for SSB occurring in series (B).

Minutes 
Table 2 Characteristics of colonic myoelectrical activity associated with constipation, diarrhoea, and pain

\begin{tabular}{|c|c|c|c|c|c|c|}
\hline \multirow[b]{2}{*}{ Patient } & \multicolumn{2}{|c|}{ Long spike bursts } & \multicolumn{2}{|c|}{ Short spike bursts } & \multirow[b]{2}{*}{$\begin{array}{l}\text { Total postprandial } \\
\text { 'rushes' }\end{array}$} & \multirow[b]{2}{*}{$\begin{array}{l}\text { Total spiking } \\
\text { activity }(\%)\end{array}$} \\
\hline & Duration (s) & Frequency/h & Duration $(s)$ & Frequency/h & & \\
\hline \multicolumn{7}{|c|}{ Constipation } \\
\hline 1 & $26 \cdot 7$ & $13 \cdot 6$ & 1.4 & 99 & 4 & 26 \\
\hline 2 & 18.4 & 6.7 & $2 \cdot 5$ & 111 & - & 21 \\
\hline 3 & $23 \cdot 5$ & 20.8 & $1 \cdot 6$ & 144 & - & 30 \\
\hline 4 & $21 \cdot 4$ & $23 \cdot 6$ & $3 \cdot 7$ & 202 & 5 & 46 \\
\hline 5 & $22 \cdot 9$ & $10 \cdot 4$ & $2 \cdot 6$ & 126 & 2 & 31 \\
\hline 6 & $15 \cdot 4$ & 14.5 & 1.9 & 292 & 4 & 38 \\
\hline 7 & 15.8 & $23 \cdot 8$ & 1.8 & 111 & 5 & 35 \\
\hline 8 & 12.4 & $9 \cdot 2$ & $3 \cdot 2$ & 212 & 6 & 41 \\
\hline 9 & $25 \cdot 6$ & $9 \cdot 4$ & $2 \cdot 6$ & 181 & 5 & 37 \\
\hline 10 & $17 \cdot 2$ & 6.9 & $2 \cdot 4$ & 146 & 3 & 29 \\
\hline 11 & $30 \cdot 8$ & $13 \cdot 4$ & $3 \cdot 6$ & 163 & - & 24 \\
\hline 12 & 23.9 & 15.6 & $2 \cdot 9$ & 217 & 2 & 39 \\
\hline 13 & $25 \cdot 3$ & $20 \cdot 6$ & $2 \cdot 3$ & 112 & - & 32 \\
\hline \multicolumn{7}{|c|}{ Diarrhoea } \\
\hline 14 & $27 \cdot 4$ & $4 \cdot 5$ & - & 一 & 2 & $3 \cdot 2$ \\
\hline 15 & $36 \cdot 6$ & $2 \cdot 8$ & 一 & - & 1 & $2 \cdot 9$ \\
\hline 16 & $20 \cdot 7$ & $7 \cdot 6$ & - & - & 4 & $8 \cdot 1$ \\
\hline 17 & $21 \cdot 6$ & $6 \cdot 4$ & - & - & 1 & $7 \cdot 2$ \\
\hline 18 & $27 \cdot 5$ & $3 \cdot 3$ & - & - & 1 & $3 \cdot 1$ \\
\hline 19 & $23 \cdot 4$ & $7 \cdot 2$ & - & - & 2 & $5 \cdot 4$ \\
\hline \multicolumn{7}{|c|}{ Abdominal pain related to meals } \\
\hline 20 & $17 \cdot 4$ & $16 \cdot 4$ & 1.8 & 13 & - & 13 \\
\hline 21 & $13 \cdot 2$ & $25 \cdot 3$ & $2 \cdot 6$ & 22 & - & 19 \\
\hline 22 & $21 \cdot 3$ & $15 \cdot 3$ & $2 \cdot 5$ & 10 & - & 16 \\
\hline
\end{tabular}

6 to 17 spike bursts which were not part of a series and lasted $7 \cdot 2 \pm 2 \cdot 1 \mathrm{~s}$ - that is, less than a LSB and much more than a SSB. They were propagated aborally at a very high velocity $(10.5 \pm 2.6 \mathrm{~cm} / \mathrm{s})$ along the whole region of the colon that was investigated. To distinguish them from the two other types of potentials, they were termed 'postprandial rushes'.

\section{CHANGES ASSOCIATED WITH PAIN,} CONSTIPATION, OR DIARRHOEA

Three main abnormal patterns were identified (Table 2). In 13 patients, (group I), the spiking activity was characterised by an increase in the presence of SSB occurring at a minimal frequency of 100 per hour in place of 11-80 in control subjects. The hourly duration of SSB activity was increased by $48 \%$. Figure 3 shows a typical record obtained in such patients. Clinical examination revealed that 10 patients of this group were chronically constipated, four of them and the three remaining patients presenting localised and intermittent abdominal pain, associated in $78 \%$ of the cases with the presence of strong and sometimes fused SSB (see Fig. 3).

A total spiking activity occupying only 3 to $8 \%$ of the recording time was observed in six patients (group II), the electromyograms being characterised

Table 3 Colonic myoelectrical activity in health and functional disorders presented in three groups: constipation (I), diarrhoea (II), abdominal pain (III)

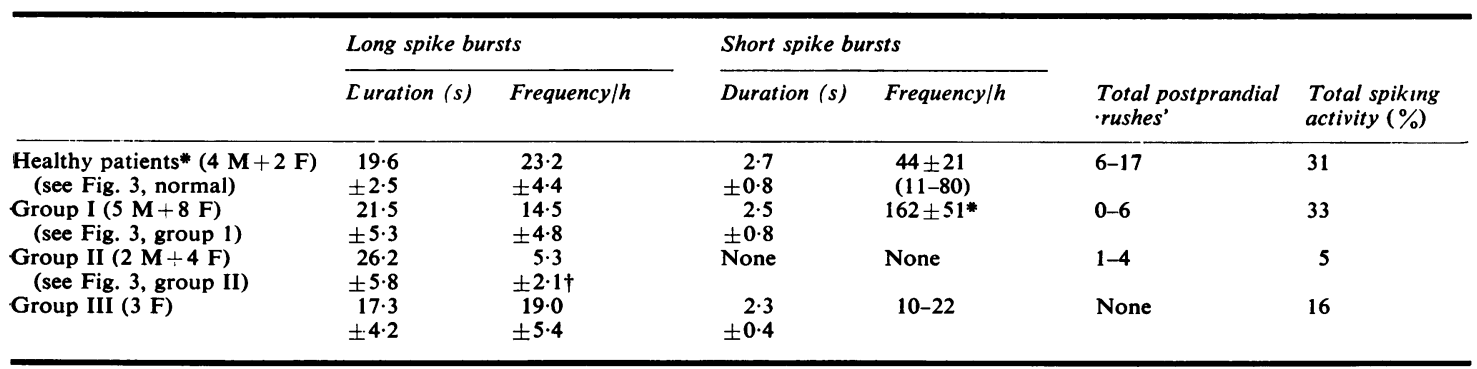

*Men (M) and women (F). Each value represents the mean \pm SD for a 10 hour recording session of six subjects.

†Significant differences $(\mathrm{P}<\mathbf{0 . 0 5})$ with values observed in healthy subjects. Total spiking activity is expressed as a percentage of recording time. 


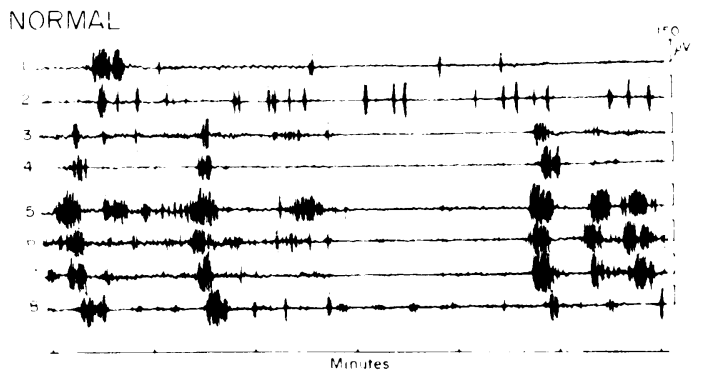

GROUP I

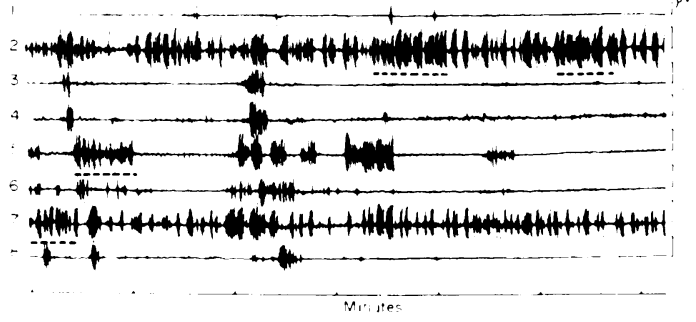

GROUP 11

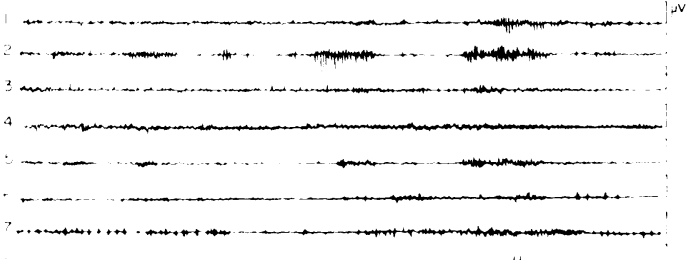

.

Fig. 3 Colonic EMG records for one healthy bowel (normal) and for disturbances associated with chronic constipation and abdominal pain (group I) or with diarrhoea (group II). For group I, dotted line indicates four sequences of SSB associated with abdominal pain.

by the absence of SSB. These typical changes were associated with a reduction of the LBS occurrence which did not exceed 5 per hour (Fig. 3). In most of the cases LSB duration was increased (see Table 2) and their amplitude decreased (Fig. 3). All these patients had episodic watery diarrhoea with a high daily frequency of defaecation and in one case, diffuse abdominal pain.

In both of these groups, the presence of postprandial peristaltic 'rushes' was reduced compared with healthy subjects, although their amplitude and duration were unchanged (Table 3). However, these rushes were absent altogether in three other patients presenting a subnormal spiking pattern (group III). These patients did not present well-defined clinical symptoms of functional colonic disorders but only a chronic sensation of postprandial pain with a tendency towards constipation in two of them and psychic disturbance in the third.

\section{Discussion}

The system used to record colonic motility described here offers a new means for investigation of colonic motor disturbances based on a stable and reproducible control pattern. Its validity was confirmed by the similarity between the slow-wave pattern obtained and those of previous workers. ${ }^{2-4}$ Two technical features allowed the recording of action potentials to be achieved, as well as the description for the first time in humans of their forms as long and short spike bursts and also their temporal organisation. The first was the nature of the electrodes: nickel-chrome wire of small diameter $(0.12 \mathrm{~mm})$ seems to be necessary to pick up action potentials and to minimise artefacts caused by the patients' movements. The second was the use of a short time constant $(0.1 \mathrm{~s}$ or less) for selective detection of spike bursts (low cut-off frequency of the filter set at $0.5 \mathrm{~Hz}(-3 \mathrm{~dB})$. Another point of great importance in ensuring electrical contact might be the absence of bowel clearance.

Previous experiments performed in man with a recording system limited to slow-wave detection suggested that some mechanical contractions were correlated with slow waves, ${ }^{4}$ an association contrary to that established for both gastric and intestinal smooth muscle. ${ }^{7}$ The present study suggests that the apparent finding of contractions without spikes merely reflected the inability of the recording technique to detect spikes. The two kinds of spike bursts described here were correlated with mechanical activity and have been observed previously in the colon of both the dog and the pig. ${ }^{6} 8$

Perhaps the greatest interest of this study is the detection of characteristic changes in the basic pattern associated with functional colonic disorders. A striking feature is the occurrence of series of short spike bursts of high amplitude synchronised with the sensation of abdominal pain. This result is in accordance with the periods of pressure waves developed at a similar frequency during episodic pain in 'spastic colon' disease. ${ }^{9}$

Chronic diarrhoea was the most common clinical sign of group II, which was characterised by the absence of SSB and a low spiking activity level. This feature, which is in agreement with the typical absence of phasic pressure waves in the pelvic colon, ${ }^{\mathbf{1 0}}$ is unlikely to be related to abnormal electrode contact, as spike bursts corresponding to postprandial rushes were of normal amplitude during these periods of low spiking activity level. These results suggest that LSB may be related to a peri- 
staltic and propulsive activity, whereas SSB are related to a segmenting and mixing activity possibly serving as a pressure barrier that opposes the propulsive effect of the former spiking form.

The significance of postprandial peristaltic rushes is not clear. If their occurrence prevents the distension of the caecum and the ascending part of the colon when the ileal flow of digesta is increased after a meal, their absence might be associated with distension of the caecum and ascending colon accompanied by abdominal pain or discomfort.

\section{References}

${ }^{1}$ Misiewicz JJ. Colinic motility. Gut 1975; 16: 311-4. ${ }^{2}$ Couturier C, Roze C, Couturier-Turpin MH, Debray C. Electromyography of the colon in situ. An experimental study in man and in the rabbit. Gastroenterology 1969; 56: 317-322.

${ }^{3}$ Taylor I, Smallwood R, Duthie HL. Myoelectric activity in the recto-sigmoid in man. In: Daniel EE, et al., eds. Proceedings of the 4th international symposium on gastrointestinal motility, Banff, Alta. 1973. Vancouver: Mitchell Press, 1974: 109-119.
${ }^{4}$ Snape WJ, Carlson GM, Cohen S. Colonic myoelectric activity in the irritable bowel syndrome. Response to prostigmine and the gastro-intestinal hormones. In: Vantrappen G, ed. Proceedings of the 5th international symposium on gastrointestinal motility, Leuven 1975. Herentals Typoff: Press, 1976: 434-40.

${ }^{5}$ Taylor I, Duthie HL, Smallwood R, Linkens D. Human large bowel myoelectrical activity. In: Vantrappen G, ed. Proceedings of the 5th international symposium on gastrointestinal motility, Leuven 1975. Herentals: Typoff Press, 1976: 429-33.

${ }^{6}$ Bueno L, Garcia-Villar R, Ruckebusch Y. Activite electrique du colon chez le chien eveille. CR Adad Sci (D) Paris 1977; 285: 1463-6.

${ }^{7}$ Bass P, Wiley JN. Electrical and extraluminal contractile force activity of the duodenum of the dog. Am J Dig Dis. 1965; 10: 173-200.

${ }^{8}$ Fioramonti J, Bueno L. Electrical activity of the large intestine in normal and megacolon pigs. Ann Rech Vétér 1977; 8: 275-83.

${ }^{9}$ Holdstock DJ, Misiewicz JJ, Waller SL. Observations on the mechanism of abdominal pain. Gut 1969; 10: 19-31.

${ }^{10}$ Connell AM. The motility of the pelvic colon. II. Paradoxical motility in diarrhoea and constipation. Gut 1962; 3: 342-8. 